\title{
Simple Preparation of Honeycomb-like Macrostructured and Microporous Carbons with High Performance in Oxidative Dehydrogenation of Ethylbenzene
}

\author{
Lifeng Wang, Jian Zhang ${ }^{+}$, Dang Sheng $\mathrm{Su}^{+}$, Yanyan Ji, Xuejing Cao, and Feng-Shou Xiao* \\ State Key Laboratory of Inorganic Synthesis and PreparatiVe Chemistry \& College of Chemistry, Jilin University, \\ Changchun 130012, China \\ ${ }^{+}$Department of Inorganic Chemistry, Fritz Haber Institute of the Max Planck Society, Faradayweg 4-6, 14195 \\ Berlin, Germany. \\ * To whom correspondence should be addressed. Fax: +86-(431)-5168624. E-mail: fsxiao@mail.jlu.edu.cn.
}

Honeycomb-like macrostructured carbons with well-defined microporosity have been prepared from the microwave popping of maize followed by thermal carbonization. The obtained carbon material shows good catalytic activity over oxidative dehydrogenation of ethylbenzene to styrene.

\section{Introduction}

Porous carbon materials are very important for potential applications in adsorption, ${ }^{1}$ separation, ${ }^{2}$ catalysis, ${ }^{3}$ electric double-layer capacitors, and lithium-ion batteries. ${ }^{4}$ Among them, activated carbon (AC) and carbon molecular sieve (CMS) have been widely applied in catalysis and adsorption. However, the traditional activation process in AC sometimes comes with equipment corruption and impurities induced by the chemicals or energy cost from hot gases. ${ }^{5,6} \mathrm{CMS}$ is generally accompanied by relatively small porosity and complex operation. ${ }^{6}$

Recently, template methods have been extensively developed to synthesize porous carbons. Kyotani et al., ${ }^{7}$ Mallouk et al., and Rodriguez-Mirasol et al. ${ }^{8}$ prepared microporous carbon using zeolite as the rigid template. Ryoo et al. ${ }^{9}$ and Hyeon et al. ${ }^{10}$ developed a nanocasting method to synthesize mesoporous carbon from mesoporous silica, and this method has been further explored. ${ }^{11-14}$ More recently, Zhao et al., ${ }^{15}$ Dai et al., ${ }^{16}$ and Ueyama et al. ${ }^{17}$ developed facile routes to mesoporous carbon by assembly of block copolymers with polymeric carbon precursor followed by removal of block copolymers and carbonization. Although there are many encouraging advances in recent years, template synthesis of porous carbon remains challenging for wide applications because of the complicated procedures, costly templates, and caustic chemical treatment. .,11b,18 $^{2}$

Herein, we report a simple and environmentally benign preparation of honeycomb-like macrostructured and microporous carbons with adjustable surface area and porosity from the microwave popping of maize followed by thermal carbonization.

\section{Experimental Section}

Synthesis. The microporous carbons with honeycomb-like macrostructure were prepared as follows: (1) The yellow maizes were settled in a sealed vessel and treated carefully in a microwave oven (700 W, Haier-6701AU) for 2-4 min. During microwave treatment the maizes were expanded with cracks and the popped maizes (popcorn) obtained. (2) The popped maizes were heated to the desired temperature $\left(T /{ }^{\circ} \mathrm{C}\right)$ and maintained for 2-4 $\mathrm{h}$ in the nitrogen atmosphere, which are designated as popcarbon- $T(T)$ ) 600, 750, $900{ }^{\circ} \mathrm{C}$ ). The yield of popcarbon- 900 is about $10 \%$. The particle size is about $4-15 \mathrm{~mm}$. The morphology of popcarbon is fragile.

For comparison, direct carbonization of maize was carried out under the same process as the popcarbon materials in the absence of microwave treatment.

\section{Characterization.}

Scanning electron microscopy (SEM) experiments were performed on a JSM-6700F electron microscope (JEOL, Japan). Transmission electron microscopy (TEM) experiments were performed on a JEM-3010 electron microscope (JEOL, Japan). The nitrogen isotherms were measured at $77 \mathrm{~K}$ using a Micrometeritics ASAP 2010 system. The samples were outgassed for $10 \mathrm{~h}$ at $300{ }^{\circ} \mathrm{C}$ before the measurements. The moisture content of the sample was measured by oven drying at $103^{\circ} \mathrm{C}$. The sample 
was cooled in a desiccator before weighting. The bulk density of popcarbon-900 is $0.14 \mathrm{~g} / \mathrm{cm} 3$ (popcarbon was crushed into a powdery morphology before measurement). The ash content of maize is about $1.1 \%$ with a major composition of $\mathrm{Si}, \mathrm{Mg}$, and $\mathrm{Fe}$ (weight ratio: $14 \mathrm{Si} / 15 \mathrm{Mg} / \mathrm{Fe}$ ) determined by inductively coupled plasma analysis (ICP, Perkin-Elmer 3300DV).

\section{Catalytic Test.}

Oxidative dehydrogenation (ODH) of ethylbenzene to styrene reaction was carried out in a quartz tube reactor $\left(8 \mathrm{~mm}\right.$ i.d. _ $300 \mathrm{~mm}$ ) at $400{ }^{\circ} \mathrm{C}$ and atmospheric pressure. A $50 \mathrm{mg}$ amount of catalyst particles (100-200 $\mu \mathrm{m})$ was held between two quartz wool plugs in the isothermal zone. The reactant was a flowing mixture with 2.8 vol. \% EB (O/EB ratio of 1, Helium as the dilutent), and the total space velocity was $12000 \mathrm{~mL} / \mathrm{g} \mathrm{h}$. The inlet and outlet gas analyses were performed on an on-line gas chromatograph (Varian-3800) equipped with the FID and TCD detectors.

\section{Results and Discussion}

Maize is popped under microwave radiation (popcorn) followed by thermal carbonization at different temperatures (600-900 ${ }^{\circ} \mathrm{C}$, popcarbon- $T$ where $T$ represents the carbonization temperature) in a flowing nitrogen atmosphere. Figure 1 shows SEM images of popcorn and popcarbon-900 as well as the TEM image of popcarbon-900. Notably, the popcorn (Figure 1A) shows a honeycomb-like macrostructure with pore sizes of 30-40 $\mu \mathrm{m}$. Interestingly, popcarbon-900 basically retains the honeycomb-like macrostructure with pore sizes of 20-30 $\mu \mathrm{m}$ (Figure 1B), indicating the successfully macrostructured transformation from popcorn to popcarbon during the treatment of carbonization. The smaller pore sizes of honeycomb-like macrostructure can be related to wall shrinkage during carbonization.
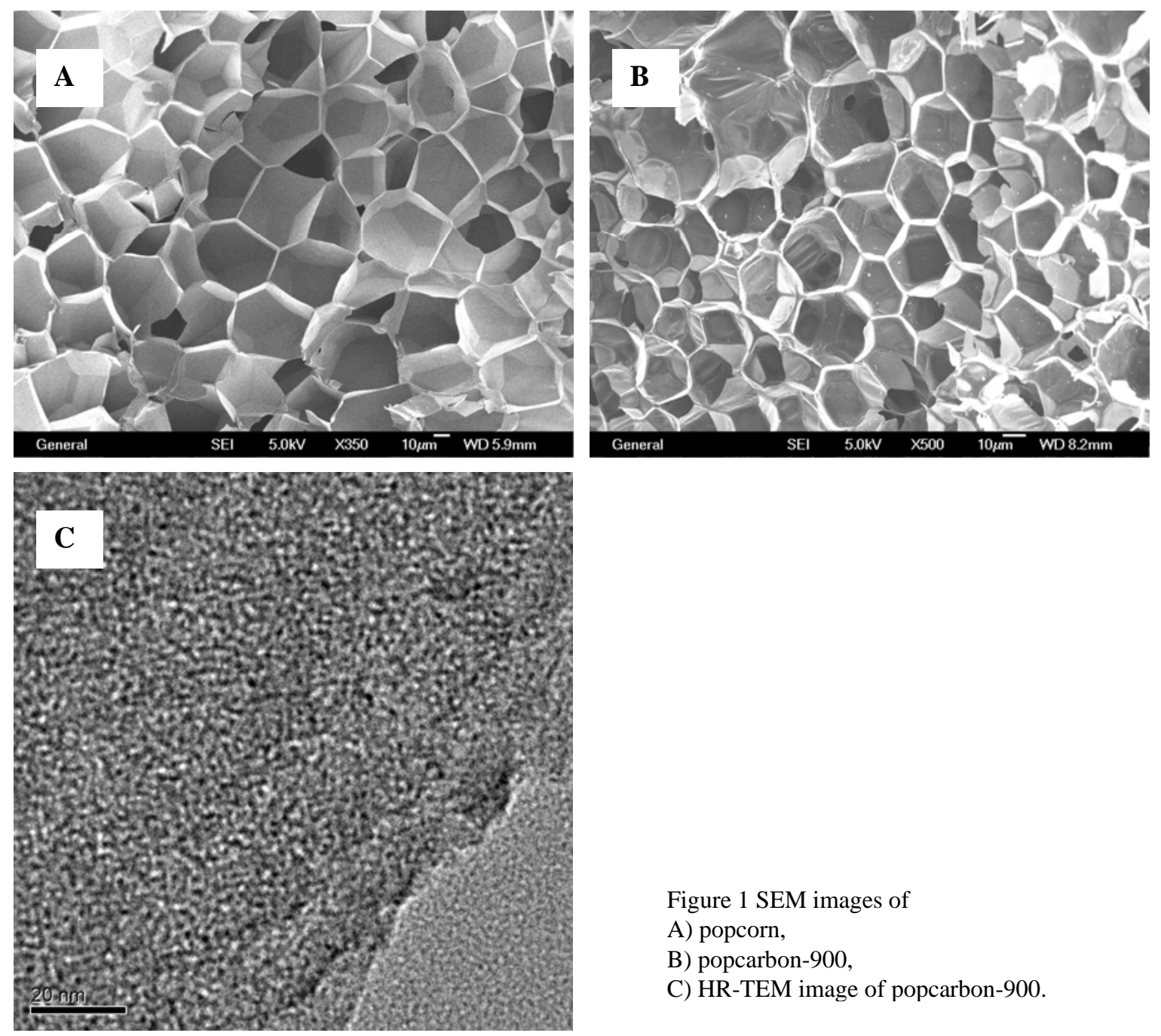

Figure 1 SEM images of
A) popcorn,
B) popcarbon-900,
C) HR-TEM image of popcarbon-900. 
The TEM image (Figure 1C) shows that disordered micropores are distributed in popcarbon-900. Figure 2 shows nitrogen isotherms of popcarbon materials carbonized at various temperatures. All the samples (popcarbon-600, -750, -900) show a steep increase in the curve at a relatively low pressure $(p / p 0<0.1)$, indicating the presence of micropores. Obviously, the surface area and pore volume of popcarbon materials increase with carbonization temperatures. Popcarbon- 600, -750, and -900 exhibit a BET surface area of 589, 773, and $1417 \mathrm{~m} 2 / \mathrm{g}$, respectively, and a micropore volume of $0.23,0.30$, and 0.46 $\mathrm{cm} 3 / \mathrm{g}$ (Figure 2 and Table 1). In contrast, the sample from direct carbonization of maize at $900{ }^{\circ} \mathrm{C}$ without prior popping shows a very low BET surface area $(36 \mathrm{~m} 2 / \mathrm{g})$ and micropore volume $(<0.02 \mathrm{~cm} 3 /$ $\mathrm{g}$ ), indicating that there is almost no microporosity in the sample. Moreover, we cannot observe a honeycomb-like macrostructure from the SEM image of the direct carbonized sample (Supporting Information, Figure 1). These results demonstrate that microwave popping is a key step for formation of honeycomb-like macrostructure and microporosity in popcarbon materials.

Considering the process of microwave popping, it is suggested that steaming explosion may be responsible for formation of the honeycomb-like macrostructure and microporosity in popcarbon materials. To validate this hypothesis, microwave popping of maize with various moistures $(7.2,10.4$, $12.5,14.1,16.3,19.5 \mathrm{wt} \%$ ) has been performed. The obtained results show that maize with a moisture content of $14.1 \mathrm{wt} \%$ gives the most expanded popcorn. In contrast, it is difficult to observe the expanded popcorn when maize moisture is less than $7.2 \mathrm{wt} \%$ or more than $19.5 \mathrm{wt} \%$. Generally, steaming explosion in maize is dependent on the strength of the pericarp and pressure of steam formed inside the pericarp. ${ }^{19,20}$ Possibly, when the maize moisture content is less than $7.2 \mathrm{wt} \%$ the steam formed under microwave radiation may lack enough pressure to burst the pericarp; when the maize moisture content is more than $19.5 \mathrm{wt} \%$, the strength of the pericarp may be reduced significantly and expanded popcorn cannot be formed. In our case, compared with original maize, the weight loss of popping maize is $13.2 \mathrm{wt}$ $\%$, which is close to the original moisture content in maize (14.1 wt \%). The hexagonal structure in the beehive is a wonderful example of a way to minimize material or energy in nature, as stated by the famous "Honeycomb Conjecture" in mathematics. ${ }^{21}$ The hexagonal prism holds more holes for the same amount of carbon used in constructing a macroporous structure. In this case, the steam from a dissociative water molecule in fresh maize could be much more discharged.

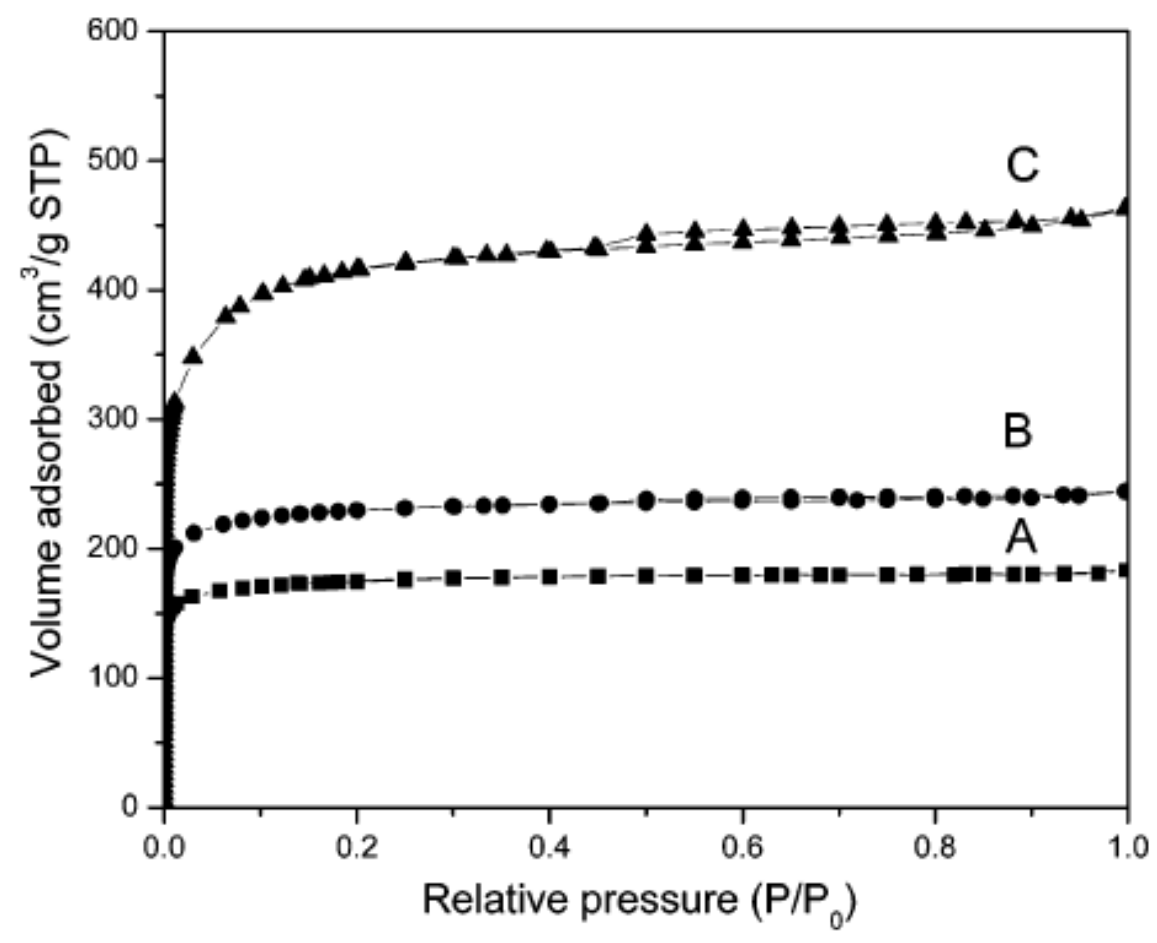

Figure 2 Nitrogen isotherms of popcarbon: (A) popcarbon-600, (B) popcarbon-750, and (C) popcarbon-900.

It is worth noting that microwave popping is an environmentally benign and effective route for formation of porosity, which also avoids the traditional chemical or physical activation process. Our method presented here may be available for preparation of porous carbon materials using other raw cereals such as wheat, barley, and rice. Additionally, obtained popcarbon materials have adjustable pore volume and 
surface area as well as the honeycomb-like macrostructure, while most carbon materials are in the morphology of particles, tube, and fibers. These structural features should be helpful for their potential applications in absorbent, catalysts, and catalyst supports.

The synthesized popcarbon is tested as catalyst for oxidative dehydrogenation of ethylbenzene to styrene. Styrene as a monomer for synthetic polymers is one of the 10 most important industrial chemicals. ${ }^{22}$ The conventional route is direct dehydrogenation of ethylbenzene over the iron oxide catalyst at high temperature, i.e., $600-630{ }^{\circ} \mathrm{C}$. A sufficient amount of steam is always required to provide energy and improve the stability of metal catalysts. Therefore, there is a great effort to develop an applicable alternative route with less energy consumption, i.e., oxidative dehydrogenation (ODH) of ethylbenzene, by using oxygen ${ }^{23-27}$ However, molecular oxygen always causes deep oxidation into COx, which greatly lowers the atomic efficiency of feedstock. Till now, it has been still challenging to achieve a high selectivity as well as a favorable yield of styrene.

Table 2 compares the catalytic activity of popcarbon toward the ODH of ethylbenzene with typical catalysts in the literature. ${ }^{23-27}$ Even at relatively low temperature and high space velocity the popcarbon900 sample possesses a high catalytic performance. At $400{ }^{\circ} \mathrm{C}$ and total space velocity of $18000 \mathrm{~mL} / \mathrm{g} \mathrm{h}$, the obtained reaction rate is $6.2 \mathrm{mmol}-\mathrm{ST} / \mathrm{g}$ h while the selectivity to styrene is $86 \%$. Over the continuous reaction for $400 \mathrm{~min}$ the styrene yield slightly decreased from $40.3 \%$ to $32.3 \%$ while the selectivity always remained at around 85\% (Supporting Information, Figure 2). The catalytic evaluation strongly suggested that the synthesized popcarbon is a promising catalyst for styrene synthesis from ODH of ethylbenzene.

Table 1. Textural parameters of popcarbon samples treated at various temperatures.

\begin{tabular}{ccccc}
\hline Sample & $\begin{array}{c}\mathrm{S}_{\text {BET }}{ }^{\mathrm{a}} \\
\left(\mathrm{m}^{2} / \mathrm{g}\right)\end{array}$ & $\begin{array}{c}\mathrm{S}_{\text {LANGMURR }}{ }^{\mathrm{b}} \\
\left(\mathrm{m}^{2} / \mathrm{g}\right)\end{array}$ & $\begin{array}{c}\mathrm{S}_{\text {MICRO }}{ }^{\mathrm{c}} \\
\left(\mathrm{m}^{2} / \mathrm{g}\right)\end{array}$ & $\begin{array}{c}\mathrm{V}_{\text {MICRO }}{ }^{\mathrm{d}} \\
\left(\mathrm{cm}^{3} / \mathrm{g}\right)\end{array}$ \\
\hline popcarbon-600 & 589 & 776 & 505 & 0.23 \\
popcarbon-750 & 773 & 1022 & 650 & 0.30 \\
popcarbon-900 & 1417 & 1896 & 993 & 0.46 \\
\hline
\end{tabular}

${ }^{a}$ BET surface area. ${ }^{b}$ Langmuir surface area. ${ }^{\mathrm{c}} t$-Plot micropore area. ${ }^{\mathrm{d}} t$-Plot micropore volume.

Table 2. Catalytic activities of different catalysts in the oxidative dehydrogenation of ethylbenzene.

\begin{tabular}{|c|c|c|c|c|c|c|}
\hline Catalyst & $\begin{array}{l}\mathrm{O} / \mathrm{EB} \\
\text { ratio }\end{array}$ & $\begin{array}{c}\mathrm{SV} \\
(\mathrm{mL} / \mathrm{g} \\
\mathrm{h})\end{array}$ & $\begin{array}{c}\mathrm{T} \\
\left({ }^{\circ} \mathrm{C}\right)\end{array}$ & $\begin{array}{c}\text { EB } \\
\text { conversion } \\
(\%) \\
\end{array}$ & $\begin{array}{c}\text { ST } \\
\text { selectivity } \\
(\%)\end{array}$ & $\begin{array}{c}\text { Reaction } \\
\text { rate } \\
\text { (mmol-ST/gh) }\end{array}$ \\
\hline Popcarbon-900 & 1 & 12000 & 400 & 48 & 86 & 6.2 \\
\hline $20 \% \mathrm{~V}-\mathrm{Mg}-\mathrm{O}{ }^{23}$ & 2 & 18000 & 530 & 32 & 96 & 11 \\
\hline MWCNTs ${ }^{24 a}$ & 2 & 14000 & 450 & 50 & 68 & 2.7 \\
\hline Onion-like carbon ${ }^{25 a}$ & 2 & 5300 & 517 & 90 & 72 & 3.0 \\
\hline $6 \% \mathrm{~V} / \mathrm{CeZr} / \mathrm{SiO}_{2}{ }^{26 \mathrm{a}}$ & 3 & 1800 & 400 & 20 & 92 & 2.0 \\
\hline $\mathrm{FePO}_{4}-\mathrm{A}-450^{27}$ & 2 & 3640 & 440 & 24 & 86 & 0.16 \\
\hline $\mathrm{AlPO}_{4}{ }^{27}$ & 2 & 3640 & 440 & 44 & 99 & 0.35 \\
\hline
\end{tabular}

${ }^{\text {a }}$ Reaction data was acquired after the reaction lasted for $240 \mathrm{~min}$.

\section{Conclusion}


We demonstrated a simple and environmentally benign preparation of honeycomb-like macrostructured and microporous carbon materials from microwave popping and thermal carbonization of maize. Steaming explosion in the maize under microwave radiation is a key factor for formation of macrostructure and microporosity. The prepared carbon materials show adjustable pore volumes and surface areas as well as a high catalytic performance on oxidative dehydrogenation of ethylbenzene to styrene.

Acknowledgment. This work was supported by the National Natural Science Foundation of China (20573044), PPP, and State Basic Research Project of China (2004CB217804).

The authors thank Dr. J.-P. Tessonnier for helpful discussion.

\section{References}

(1) Hartmann, M.; Vinu, A.; Chandrasekar, G. Chem. Mater. 2005, 17, 829.

(2) Shiflett, M. B.; Foley, H. C. Science 1999, 285, 1902.

(3) (a) Joo, S. H.; Choi, S. J.; Oh, I.; Kwak, J.; Liu, Z.; Terasaki, O.; Ryoo, R. Nature 2001, 412, 169. (b) Lu, A.-H.; Schmidt, W.; Matoussevitch, N.; Bo"nnemann, H.; Spliethoff, B.; Tesche, B.; Bill, E.; Kiefer, W.; Schu"th, F. Angew. Chem., Int. Ed. 2004, 43, 4303.

(4) Chai, G. S.; Shin, I. S.; Yu, J.-S. AdV. Mater. 2004, 16, 2057.

(5) Lee, J.; Kim, J.; Hyeon, T. AdV. Mater. 2006, 18, 2073.

(6) (a) Jasra, R. V. et al. Sep. Sci. Technol. 1991, 26, 885. (b) Shen, Z. New Materials and Applied

Technology: New Carbon Materials; Chemical Industry Press: Beijing, 2003.

(7) Kyotani, T.; Nagai, T.; Inoue, S.; Tomita, A. Chem. Mater. 1997, 9, 609.

(8) (a) Johnson, S. A.; Brigham, E. S.; Olliver, P. J.; Mallouk, T. E. Chem. Mater. 1997, 9, 2448. (b)

Rodriguez-Mirasol, J.; Cordero, T.; Radovic, L. R.; Rodriguez, J. J. Chem. Mater. 1998, 10, 550.

(9) Ryoo, R.; Joo, S. H.; Jun, S. J. Phys. Chem. B 1999, 103, 7743.

(10) Han, S.; Hyeon, T. Chem. Commun. 1999, 1955.

(11) (a) Schu"th, F. Angew. Chem., Int. Ed. 2003, 42, 3604. (b) Lu, A.-H.; Schüth, F. AdV. Mater. 2006, 18, 1793.

(12) Xia, Y. D.; Mokaya, R. AdV. Mater. 2004, 16, 886.

(13) Pang, J.; John, V. T.; Loy, D. A.; Yang, Z.; Lu, Y. AdV. Mater. 2005, 17, 704.

(14) Taguchi, A.; Smått, J.-H.; Linde'n, M. AdV. Mater. 2003, 15, 1209.

(15) Meng, Y.; Gu, Dong.; Zhang, F.; Shi, Y.; Yang, H.; Li, Z.; Yu, C.; Tu, B.; Zhao, D. Angew. Chem., Int. Ed. 2005, 44, 7053.

(16) Liang, C.; Hong, K.; Guiochon, G. A.; Mays, J. W.; Dai, S. Angew. Chem., Int. Ed. 2004, 43, 5785.

(17) Tanaka, S.; Nishiyama, N.; Egashira, Y.; Ueyama, K. Chem. Commun. 2005, 2125.

(18) Le'onard, A.; Su, B.-L. Chem. Commun. 2004, 1647. 2894 Chem. Mater. 2007, 19, 2894-2897

(19) Shimoni, E.; Dirks, E. M.; Labuza, T. P. Lebensm.-Wiss. Technol.

(20) Hoseney, C. R. Principles of cereal science and technology, 2nd ed.; American Association of Cereal Chemists, Inc.: 1994; p 312.

(21) Peterson, I. Sci. News 1999, 156, 60.

(22) Burri, D. R.; Choi, K. M.; Han, D.-S.; Koo, J.-B.; Park, S.-E. Catal. Today 2006, 115, 242.

(23) Oganowski, W.; Hanuza, J.; Kepin'ski, L. Appl. Catal. A: Gen. 1998, 171, 145.

(24) Pereira, M. F. R.; Figueiredo, J. L.; OÄ rfa o, J. J. M.; Serp, P.; Kalck, P.; Kihn, Y. Carbon 2004, 42, 2807.

(25) Keller, N.; Maksimova, N. I.; Roddatis, V. V.; Schur, M.; Mestl, G.; Butenko, Y. V.; Kuznetsov, V. L.; Schlo"gl, R. Angew. Chem., Int. Ed. 2002, 41, 1885.

(26) Reddy, B. M.; Lakshmanan, P.; Loridant, S.; Yamada, Y.; Kobayashi, T.; L.-Cartes, C.; Rojas, T. C.; Ferna'ndez, A. J. Phys. Chem. B 2006, 110, 9140.

(27) Bautista, F. M.; Campelo, J. M.; Luna, D.; Marinas, J. M.; Quirós, R. A.; Romero, A. A. Appl.

Catal. B: EnViron. 2007, 70, 611. 


\section{Supporting information}

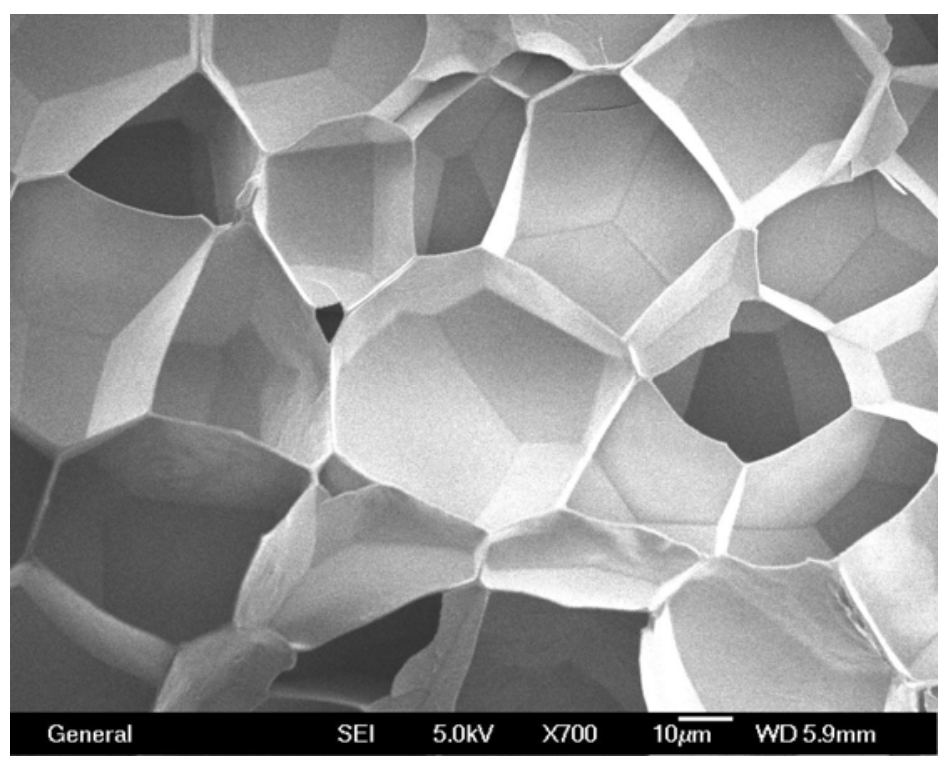

Supporting Figure 1 SEM image of popcarbon-900.

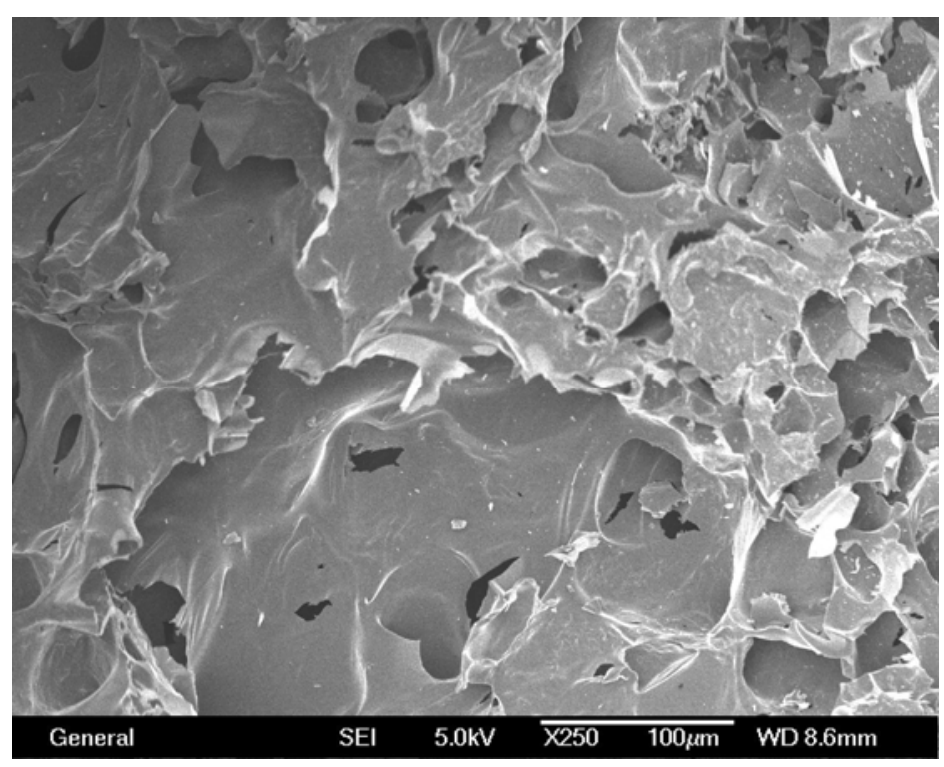

Supporting Figure 2 SEM image of carbon materials obtained from direct carbonization of maize. 